\section{P52 Children's Perspectives on the Summer Nutrition Program}

Jessica Soldavini, MPH, LDN, RD, Jessica6@live.unc.edu, No Kid Hungry NC, UNC Center for Health Promotion and Disease Prevention, University of North Carolina, 1700 Martin Luther King Jr. Boulevard, Chapel Hill, NC 27599; Maureen Berner, PhD, School of Government, University of North Carolina, Chapel Hill

Background (Background, Rationale, Prior Research, and/or Theory): The Summer Nutrition Program (SNP) provides free meals to children ages 18 and younger in low-income areas during the summer. Many SNP sites offer additional components to support the children, such as enrichment activities and free books. Attending SNP sites also gives children the opportunity to socialize with others during the summer. Little is known about the children who attend SNP sites and their perspectives on the program.

Objective: To gain an understanding of the types of children who participate in the SNP and their perspectives on the program.

Study Design, Setting, Participants, Intervention: Interview-administered surveys were conducted with a convenience sample of 55 children at 11 SNP sites from the Food for the Summer Program in Chapel Hill and Carrboro, North Carolina in August 2017.

Outcome Measures and Analysis: Children rated and provided feedback on program components, reported whether they participated in certain activities, and indicated if they had made new friends through the program. Participant demographics were also recorded.

Results: Participants ranged in age from 4 to 14 years old, with a mean age of $7.91 \pm 2.75$ years old. Approximately half of the children were girls. Twenty-five percent of children reported liking the food and $75 \%$ reported it being okay. Thirty percent of children reported liking the activities, while $70 \%$ said they were okay. Children provided feedback on favorite foods and activities, as well as items they would like to see offered. Eighty percent of children took free books and 93\% read those books. Over $80 \%$ of children reported making new friends through the program.

Conclusions and Implications: Children can provide valuable feedback on the SNP, and this feedback should be taken into account in planning menus and selecting activities. Additional research is needed on how to engage older children in the program.

Funding: Community Engagement Fellowship from the Carolina Center for Public Service at the University of North Carolina, Chapel Hill.

\section{P53 Development and Pilot Testing of a Community Based Participatory Research Obesity Prevention Program on College Campuses}

Kristin Riggsbee, BS, kolmstea@vols.utk.edu, University of Tennessee, 1215 W Cumberland Avenue, Jesse Harris Building, Room 229, Knoxville, TN 37996;
Sarah Colby, PhD, RDN; Tandalayo Kidd, PhD, RD, LPN, Kansas State University; Onikia Brown, PhD, RD, Auburn University; Adrienne White, PhD, RDN, FAND, University of Maine; Tanya Horacek, PhD, RD, Syracuse University; Melissa D. Olfert, DPH, LDN, RDN, West Virginia University; Anne Mathews, PhD, RDN, University of Florida; Kendra Kattelmann, PhD, LDN, RD, FAND, South Dakota State University; Karla Shelnutt, PhD, RD, University of Florida; Lisa Franzen-Castle, PhD, RD, University of Nebraska-Lincoln; Geoffrey Greene, PhD, $L D N, R D$, University of Rhode Island

Background (Background, Rationale, Prior Research, and/or Theory): College students are at risk for unhealthy dietary behaviors, increased stress levels, and decreased physical activity. Development of healthy lifestyle patterns in adolescence is correlated with reduced risk of obesity later in life.

Objective: To describe the process of using Community Based Participatory Research (CBPR) to develop and pilot test a health promotion intervention designed to prevent unwanted weight gain among "at risk" first-year college students.

Study Design, Setting, Participants, Intervention: CBPR partners, including faculty researchers $(n=31)$, student researchers $(\mathrm{n}=154)$, Extension professionals $(\mathrm{n}=11)$, and college students $(\mathrm{n}=83)$, from 12 universities identified program objectives and behaviors to target for health promotion on college campuses. Partners used identified objectives and behaviors to develop a social marketing intervention and a pilot/feasibility test of the intervention that was delivered over 24 weeks at four intervention universities, while no change occurred at four control universities. During and following implementation, partners and a student-led multistate social marketing committee adjusted the intervention and compiled materials into a comprehensive toolkit.

Outcome Measures and Analysis: The pilot test was assessed in formative and process evaluations for key stakeholder acceptability and feasibility through weekly collaborative partner meetings, tracking social marketing engagement, weekly reports from campus coordinators (event attendance, supplies/cost, and perspectives of strength, weaknesses and modifications needed), toolkit evaluation surveys completed by student researchers and college students $(n=10)$, and town hall campus meetings. Results: An acceptable and feasible comprehensive toolkit was the final output from all data collected and analyzed, which was based on the elements of diet, physical activity, and stress management. The toolkit provides a systematic approach to assessing student health behavior and priorities, obectively measuring campus healthfulness, providing health promotion activities, using social marketing to promote health, and advocating for environmental change.

Conclusions and Implications: CBPR can be used successfully to develop an obesity prevention intervention on college campuses. The effectiveness of the CBPR developed intervention to prevent unwanted weight gain needs to be evaluated in a randomized controlled trial.

Funding: NIFA. 